\title{
Impact of congenital colour vision deficiency on education and unintentional injuries: findings from the 1958 British birth cohort
}

\author{
P Cumberland, J S Rahi, C S Peckham
}

Centre for

Paediatric

Epidemiology and

Biostatistics,

Institute of Child

Health, London

WC1N 1EH

P Cumberland

senior research fellow

J S Rahi

clinical senior lecturer

in ophthalmic

epidemiology

C S Peckham

professor of paediatric

epidemiology

Correspondence to:

J S Rahi

j.rahi@ich.ucl.ac.uk

BMJ 2004;329:1074-5

\begin{abstract}
Congenital colour vision defects (CVD) are common, inherited (most commonly X linked), non-progressive, and untreatable disorders. ${ }^{12}$ Screening children for these disorders is established practice in the United Kingdom, primarily so that those affected can be advised about occupational preclusions. ${ }^{2}$ Population based work on the broader impact of colour vision defects is, however, limited.
\end{abstract}

\section{Participants, methods, and results}

We investigated the association between CVD and education and unintentional injury in the 1958 British birth cohort. ${ }^{3}{ }^{4}$ Despite attrition, people remaining were representative of the original sample, including with respect to colour vision status. The latter was assessed in 12534 children aged 11 years using the Ishihara test, ${ }^{1}$ with CVD being the inability to identify all 24 plates. Corrected distance acuity was measured with Snellen charts. We analysed educational, perceptual, and motor skills tests done at 7,11 , and 16 years $^{34}$ together with highest educational qualification by 33 (none, below $\mathrm{O}$ level or equivalent, $\mathrm{O}$ level or equivalent, $\mathrm{A}$ level or equivalent, or higher). We converted education test scores to $\mathrm{z}$ scores $^{3}$ and assessed the effect of CVD with multivariate linear regression. We analysed unintentional injuries requiring hospital care by CVD status and sex.

Overall, 431 of 6422 boys $(6.7 \%$; $95 \%$ confidence interval $6.1 \%$ to $7.3 \%)$ and 68 of 6112 girls $(1.1 \% ; 0.8 \%$ to $1.4 \%$ ) had CVD. The distribution of corrected visual acuity did not vary by colour vision status $\left(\chi^{2}\right.$ trend, $\mathrm{P}=0.12)$. Birthweight, social class at birth, family size, and parental education, all associated with education, were accounted for in the present analysis, although not associated with CVD. ${ }^{34}$

At 7 years, CVD and mathematics and reading scores were not significantly associated, after adjust-

Inpatient and outpatient care for unintentional injuries by age, according to colour vision status and sex

\begin{tabular}{|c|c|c|c|c|c|}
\hline \multirow{2}{*}{ 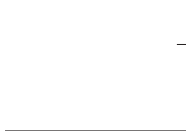 } & Normal colour vision & \multicolumn{2}{|c|}{ Colour vision defect } & \multicolumn{2}{|c|}{ Difference } \\
\hline & $\begin{array}{cc} & \text { No }(\%) \\
& \text { unintentional } \\
\text { n } & \text { injuries }\end{array}$ & $\mathrm{n}$ & $\begin{array}{c}\text { No (\%) } \\
\text { unintentional } \\
\text { injuries }\end{array}$ & $\begin{array}{c}\text { \% difference } \\
(95 \% \mathrm{Cl})\end{array}$ & $P$ value \\
\hline
\end{tabular}

\begin{tabular}{|c|c|c|c|c|c|c|}
\hline Inpatients & & & & & & \\
\hline \multicolumn{7}{|l|}{ Males } \\
\hline 0 to 16 years & 4266 & 1307 (30.6) & 316 & $86(27.2)$ & $3.4(-1.7$ to 8.5$)$ & 0.19 \\
\hline 17 to 33 years & 4058 & 805 (19.8) & 293 & 56 (19.1) & $0.7(-4.0$ to 5.4$)$ & 0.76 \\
\hline \multicolumn{7}{|l|}{ Females } \\
\hline 0 to 16 years & 4292 & $901(21.0)$ & 52 & $12(23.1)$ & -2.1 (-13.7 to 9.5$)$ & 0.73 \\
\hline 17 to 33 years & 4443 & $288(6.5)$ & 48 & $3(6.3)$ & 0.2 (-6.7 to 7.2$)$ & 0.95 \\
\hline \multicolumn{7}{|l|}{ Outpatients } \\
\hline \multicolumn{7}{|l|}{ Males } \\
\hline 11 to 16 years & 4266 & 1301 (30.5) & 316 & $101(32.0)$ & $-1.4(-6.7$ to 3.9$)$ & 0.60 \\
\hline 17 to 33 years & 4058 & 2885 (71.1) & 293 & 199 (67.9) & $3.2(-2.3$ to 8.7$)$ & 0.26 \\
\hline \multicolumn{7}{|l|}{ Females } \\
\hline 11 to 16 years & 4292 & 739 (17.2) & 52 & $11(21.2)$ & -3.9 (-15.1 to 7.3$)$ & 0.49 \\
\hline 17 to 33 years & 4444 & 1612 (36.3) & 48 & 19 (39.6) & -3.3 (-17.4 to 10.7$)$ & 0.64 \\
\hline
\end{tabular}

ment for age at testing and factors described above (table). At 16, after additional adjustment for prior test scores, children with CVD scored higher than those without; but the small differences, although statistically significant, were functionally unimportant $(0.08$ standard deviations; 0.002 to $0.16 ; \mathrm{P}=0.05$ for mathematics and $0.07 ; 0.002$ to $0.14 ; \mathrm{P}=0.04$ for reading). There were no significant differences, by colour vision status, for boys or girls, in scores for "copy a design" or "draw a man" at 7 years. Highest educational qualification and colour vision status were not associated for either men or women ( $\chi^{2}$ trend, $\mathrm{P}=0.07$ and $\mathrm{P}=0.61$ ).

Risk of unintentional injury did not differ significantly (table). Overall, $8.9 \%$ (8.2\% to $9.6 \%)$ of females and $19.2 \%(18.2 \%$ to $20.2 \%)$ of males had road injuries as a driver by 33 years; people with CVD reported fewer unintentional injuries $(\mathrm{P}=0.08$ and $\mathrm{P}=0.05)$. At 33 years, $30 \%(28.9 \%$ to $31.2 \%)$ of men reported unintentional injuries in the workplace, without any increased risk in those with colour vision defects $(\mathrm{P}=0.293)$.

\section{Comment}

Increasing use of colour in education has raised concerns for children with CVD, but robust evidence is lacking. ${ }^{5}$ Our findings indicate that affected children do as well as their peers educationally, during school and subsequently. Although the use of colour has increased since the early schooling of the subjects of this study, only a minority with severely impaired colour vision would be potentially disadvantaged and any limitation would depend on the specific environment as well as the individual's abilities.

That unintentional injuries were no more common among those with CVD supports current standards for driving in the United Kingdom (in which CVD is not a preclusion) and also indicates that normal colour vision is not a prerequisite for safe working in many occupations or environments.

Most people with colour vision defects develop effective adaptive strategies and behaviours, and they use other clues, such as a colour's saturation, to deal with any potential limitations in their professional and personal lives. ${ }^{1}$ At a population level, congenital CVD confers no functional disadvantage in relation to educational attainment and unintentional injury. This challenges the rationale for and the value of population screening for these disorders.

JR has a joint appointment within the Division of Epidemiology, Institute of Ophthalmology, London EC1V 9EL. We thank the Centre for Longitudinal Studies (Institute of Education), National Birthday Trust Fund, National Children's Bureau, City University Social Statistics Research Unit, and the Data Archive distributor, SN:3138, Colchester, for archived data. We thank Angie Wade for comments on a previous draft.

This article was posted on bmj.com on 1 October 2004: http://bmi.com/ cgi/doi/10.1136/bmj.38176.685208.F7 


\section{What is already known on this topic}

Congenital colour vision defects are common, non-progressive, and untreatable disorders, for which screening is done so that affected children can be informed about occupations which require normal colour vision

Little population based work exists on the broader functional impact of these disorders

\section{What this study adds}

At a population level, colour vision defects confer no functional disadvantages in relation to educational attainment or unintentional injury-challenging the rationale for and value of screening
Contributors: JSR designed the study; PC did the analysis; and PC, JSR, and CSP interpreted the findings and wrote the paper. JSR is guarantor.

Funding: Project grant from the BUPA Foundation. Competing interests: None declared.

Ethical approval: Institute of Child Health's Research Ethics Committee.

1 Health and Safety Executive. Colour vision. London: HMSO, 1987:1-8. (Medical series guidance notes MS7).

2 Holroyd E, Hall DMB. A re-appraisal of screening for colour vision impairments. Child Care Health Dev 1997;23:391-8.

3 Essen J, Fogelman K, Ghodsian M. Long-term changes in the school attainment of a national sample of children. Educ Res 1978;20:300-5.

4 Jefferis BJMH, Power C, Hertzman C. Birth weight, childhood socio-economic environment, and cognitive development in the 1958 British birth cohort study. BMJ 2002;325:305-8.

5 Lampe LML, Doster ME, Beal BB. Summary of three year study of academic and school achievement between color-deficient and normal primary age pupils: phase 2.J Sch Health 1973;43:309-11.

(Accepted 15 June 2004)

doi 10.1136/bmj.38176.685208.F7

\title{
DRUG POINTS
}

\section{QT interval increased after single dose of lofexidine}

\author{
John Schmittner, Jennifer R Schroeder, David H Epstein, Kenzie L Preston
}

Lofexidine (BritLofex, Britannia) is an $\alpha 2$ agonist used for opioid detoxification. ${ }^{1}$ We report one case of an increased QT interval after one dose of $0.4 \mathrm{mg}$ lofexidine. $^{2}$

A 44 year old white opiate dependent female enrolled in a protocol to assess the safety of taking daily lofexidine with daily methadone. She had no known drug allergies, took no other drugs, and had never taken lofexidine before.

An electrocardiogram before starting methadone showed sinus rhythm (70 beats/min) and QT/QTc $428 / 462 \mathrm{~ms}$. After stabilisation on methadone at $80 \mathrm{mg}$ a day, an electrocardiogram still showed sinus rhythm (67 beats/min) and QT/QTc 428/449 ms (fig). She was then given lofexidine with her daily dose of methadone, which was followed by brief hypotension $(88 / 55 \mathrm{~mm}$ $\mathrm{Hg}$ ) with mild drowsiness. Four hours after taking lofexidine, an electrocardiogram showed sinus bradycardia (58 beats/min), QT/QTc 612/601 ms, and blood pressure 149/88 $\mathrm{mm} \mathrm{Hg}$ (fig). The participant was otherwise asymptomatic. Within 24 hours, QT/QTc was 372/432 ms. Laboratory work found no abnormalities. Echocardiography showed mild mitral regurgitation.

Three independent cardiologists interpreted that although there was some QT prolongation (QT range 510-560 ms; QTc range 501-560), the computer overestimated the interval because of $\mathrm{U}$ waves.

Increased QT interval with lofexidine has been seen in animals, but only at very high doses ${ }^{3}$; no clinically important changes have been seen in humans. Although high doses of methadone have been associated with changes in QT and arrhythmia, ${ }^{4}$ the woman in this case had a normal QT interval while on methadone. The temporal relationship and lack of other causes indicate that the combination of lofexidine and methadone perhaps was the precipitant of this self limited change in QT.
In response, Britannia reported this event to the United Kingdom Committee on Safety of Medicines and added a warning to the summary of product characteristics (see www.lofexidine.co.uk). Before initiating lofexidine, clinicians may want to screen patients who might be at risk for repolarisation abnormalities.

Funding: National Institutes of Health, National Institute on Drug Abuse, Intramural Research Program, provided all funding. Britannia Pharmaceuticals Limited provided lofexidine. Competing interests: None declared.

1 Wilkins LH, Winternitz SR, Oparil S, Smith RL, Dustan HP. Lofexidine and clonidine in moderate essential hypertension. Clin Pharmacol Ther 1981;30:752-7.

2 Bednar MM, Harrigan EP, Anziano RJ, Camm AJ, Ruskin JN. The QT interval Prog Cardiovasc Dis 2001:43(5 suppl 1):S1-45.

3 Tsai TH, Beitman RE, Gibson JP, Larson EJ, Friehe H, Fontaine R. Acute, subacute and chronic toxicity/carcinogenicity of lofexidine. Arzneimittelforschung 1982;32:955-62.

4 Roden DM. Drug-induced prolongation of the QT interval. New Engl J Med 2004;350:1013-22.

National Institutes of Health, National Institute on Drug Institute on Drug Research Program, 5500 Nathan Shock Drive, Baltimore, MD 21224, USA John Schmittner clinical fellow Jennifer R Schroeder research scientis David H Epstein staff scientist

Kenzie L Preston principal investigator Correspondence to: Dr. Schmittner jschmitt@ intra.nida.nih.gov

BMJ 2004;329:1075

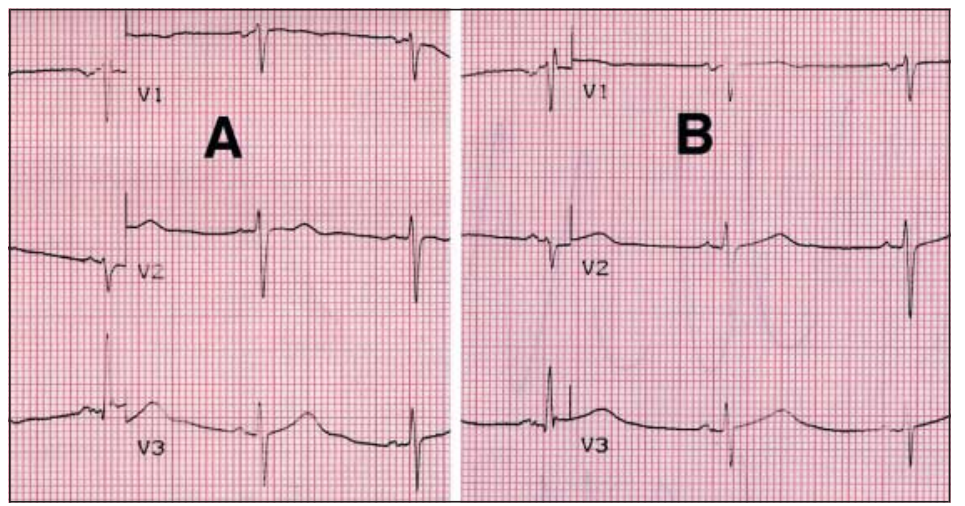

Electrocardiograms before (A) and after (B) taking lofexidine while stabilised on methadone 